\title{
GÊNERO, COTIDIANO E CÁRCERE
}

\author{
GENDER, DAILY LIFE AND PRISON \\ GÉNERO, DIARIO Y PRISIÓN
}

\author{
Felipe Henrique Oliveira da Silva ${ }^{1}$ \\ Raquel de Aragão Uchôa Fernandes ${ }^{2}$ \\ Priscilla Karla da Silva Marinho ${ }^{3}$
}

\begin{abstract}
Resumo
Dados do International Centre for Prison Studies apontam que há aproximadamente 700 mil mulheres encarceradas no mundo, e o Brasil surge como a quarta maior população carcerária feminina, conforme dados apresentados pelo Infopen de 2018. Em uma sociedade desigual as possibilidades de acesso a direitos e de bemviver são limitadas em decorrência dos atributos de classe, gênero, etnia/raça e geração. Nesta pesquisa buscamos compreender as relações e modos de vida urbanos e subalternidade, a partir do cotidiano de mulheres que vivenciaram o encarceramento. Para chegar até às mulheres firmamos uma proposta de cooperação com o Patronato Penitenciário de Pernambuco, órgão de execução penal ligado à Secretaria Executiva de Justiça e Direitos Humanos, coordenado pela Secretaria de Desenvolvimento Social e Direitos Humanos. As mulheres que compõem esta pesquisa estão ainda em cumprimento de pena fora do cárcere, sendo ouvidas durante os grupos mensais de acolhimento intitulados Diálogo entre Mulheres. A presente pesquisa é qualitativa com inspiração no método da pesquisa-ação, através da utilização dos grupos mensais como círculos de pesquisa para este trabalho. Os resultados obtidos até o momento apontam que há uma reprodução geracional de trajetórias subalternas na história de vida destas mulheres.
\end{abstract}

Palavras-chave: Mulheres. Sistema Carcerário. Patronato. Cotidiano.

\section{Abstract}

Data from the International Center for Prison Studies show that there are approximately 700,000 women incarcerated in the world, and Brazil emerges as the fourth largest female prison population, confirmed by the data presented by Infopen in 2018. In an unequal society, the possibilities of access to rights and well-living are limited due to the attributes of class, gender, ethnicity / race and generation, therefore, in this research we seek to understand the relationships between urban lifestyles and subalternity, from the daily lives of women who have experienced incarceration. To reach women, we signed a cooperation proposal with the Pernambuco Penitentiary Patronage, a criminal enforcement agency linked to the Executive Secretariat for Justice and Human Rights, coordinated by the Secretariat for Social Development and Human Rights. The women who are part of this research are still serving a sentence outside prison, being heard during the monthly reception groups, entitled: Dialogue between Women. The present research is qualitative with inspiration in the action research method, through the use of monthly groups as research circles for this work. The results obtained so far indicate that there is a generational reproduction of subordinate trajectories in the life history of these women.

Keywords: Women. Prison system. Patronage. Daily

${ }^{1}$. Discente do curso de bacharelado em Ciências do Consumo/UFRPe. Bolsista de iniciação cientifica da Facepe com a pesquisa "A vida além das grades: as trajetórias de mulheres egressas do sistema prisional de Pernambuco". E-mail: philippu.felipe@gmail.com

${ }^{2}$ Doutora em Ciências Sociais pela Universidade do Estado do Rio de Janeiro. Professora do Departamento de Ciências do Consumo da Universidade Federal Rural de Pernambuco. Coordenadora do Observatório da Família/UFRPE e do Programa CapacitaSUAS/PE. E-mail: aragaouchoa@hotmail.com

${ }^{3}$ Economista doméstica, mestra em Consumo, Cotidiano e Desenvolvimento Social PGCDS/UFRPE. Integra coordenação colegiada do Observatório da Família. E-mail: pri_facchini@yahoo.com.br 


\section{Resumen}

Los datos del Centro Internacional de Estudios Penitenciarios muestran que hay aproximadamente 700 mil mujeres en prisión en el mundo, y Brasil emerge como la cuarta población de mujeres en prisión, según los datos presentados por Infopen en 2018. En una sociedad desigual, las posibilidades de acceso a los derechos y El bienestar es limitado debido a los atributos de clase, género, etnia/raza y generación. En esta investigación buscamos comprender las relaciones y los estilos de vida urbanos y la subordinación, basados en la vida cotidiana de las mujeres que han experimentado el encarcelamiento. Para llegar a las mujeres, firmamos una propuesta de cooperación con el Patrocinio Penitenciario de Pernambuco, un organismo de cumplimiento penal vinculado a la Secretaría Ejecutiva de Justicia y Derechos Humanos, coordinado por la Secretaría de Desarrollo Social y Derechos Humanos. Las mujeres que forman parte de esta investigación siguen cumpliendo una condena fuera de la prisión, siendo escuchadas durante los grupos de recepción mensuales titulados Diálogo entre mujeres. La presente investigación es cualitativa con inspiración en el método de investigación de acción, mediante el uso de grupos mensuales como círculos de investigación para este trabajo. Los resultados obtenidos hasta ahora indican que existe una reproducción generacional de trayectorias subordinadas en la historia de vida de estas mujeres.

Palabras clave: Mujeres. Sistema penitenciario. Mecenazgo. Diario.

\section{INTRODUÇÃO}

O presente estudo tem por objetivo compreender as relações entre modos de vida e subalternidade a partir de mulheres com vivência no sistema carcerário pernambucano. A pesquisa está em andamento desde 2017, e, de modo específico, objetivamos identificar as questões relacionadas ao cotidiano das mulheres em situação de pós-cárcere, trazendo como destaque elementos constituintes de suas histórias de vida para compreender os desafios enfrentados por mulheres com passagem pelo sistema prisional pernambucano.

No primeiro momento da pesquisa trabalhamos o cárcere feminino a partir das percepções de profissionais que atuam neste universo. Identificamos que o encarceramento é uma espécie de resultado de trajetórias de subalternidade. Dinâmicas cotidianas que, inferimos, vinculam estes sujeitos ao que Jessé Souza (2009) chama provocativamente de Ralé, o que constituiria "uma classe inteira de indivíduos, não só sem capital cultural nem econômico em qualquer medida significativa, mas desprovida [...] das precondições sociais, morais e culturais que permitem essa apropriação".

No segundo momento da pesquisa analisamos as vivências destas mulheres a partir da percepção delas sobre as suas histórias de vida e o lugar/peso do cárcere em seu cotidiano. Coloca-se para a pesquisa uma espécie de continuidade do tempo e das relações do cárcere no pós-cárcere, seja porque as condições que levam a ele, tais como pobreza, abandono, violação de direitos, se faz muito presente, seja, porque a passagem pelo cárcere se torna um estigma muito pesado na trajetória destas mulheres.

Nesta pesquisa trabalhamos a partir das expressões da subalternidade nas trajetórias de mulheres com passagem pelo cárcere. Para Gayatri Spivak (2012) os subalternos 
correspondem aos alijados da fala, "as camadas mais baixas da sociedade constituídas pelos modos específicos de exclusão dos mercados, da representação política e legal, e da possibilidade de se tornarem membros plenos no estrato social dominante" (SPIVAK, 2012, p.14). Para Thompson (2011) a subalternidade está associada ao conceito de experiência, da trajetória enquanto classe em uma determinada formação social.

Segundo dados do International Centre for Prison Studies há aproximadamente 700 mil mulheres encarceradas no mundo, e o Brasil ocupa o 4ํlugar no ranking das maiores populações carcerárias femininas ${ }^{4}$. Ocorreu uma espécie de boom do encarceramento feminino no Brasil a partir dos anos 2000. O país passou de aproximadamente menos de 6 mil mulheres presas para 42 mil em 2016, o que representou um aumento de $656 \%$ em relação aos dados registrados anteriormente. Tal prerrogativa é confirmada pelos dados apresentados no Levantamento Nacional de Informações Penitenciárias sobre as Mulheres - Infopen de $2018^{5}$.

No estado de Pernambuco, a população carcerária feminina atualmente está em torno de 1.500 mulheres, e o motivo do encarceramento na maioria dos casos está vinculado ao tráfico de drogas ${ }^{6}$. Geralmente, são mulheres jovens, negras ou pardas, moradoras de periferia, com baixo grau de instrução formal, que trabalhavam em subempregos ou desempregadas, mães de no mínimo um filho e com algum parente, seja irmão, filho, marido ou companheiro preso, e que dependem da sua renda para manter as despesas familiares.

Ou seja, grande parte dessas mulheres teve (e têm) na sua realidade direitos fundamentais negligenciados. Em razão desta vulnerabilidade tornam-se elementos fáceis de serem exploradas pelos traficantes, principalmente na preparação, no armazenamento e na distribuição das drogas para os consumidores finais. Usualmente, não são as gerentes das facções ou enriquecem com esta atividade, ainda que na literatura tenhamos encontrado registros sobre uma mudança no perfil de participação das mulheres no universo do tráfico de drogas.

No entanto, ainda continuam bastante comuns os relatos de mulheres vinculadas ao tráfico por questões relacionadas às experiências da subalternidade: idosas que foram presas

\footnotetext{
${ }^{4}$ Nas primeiras posições do ranking temos o Estados Unidos, China e a Rússia em relação ao tamanho absoluto da população prisional feminina.

${ }^{5}$ Publicado pela primeira vez em 2014, o Infopen - Mulheres é fruto de um levantamento de dados sobre o universo prisional feminino. As projeções de aumento do encarceramento de mulheres no país demonstraram a importância da elaboração, ainda no ano de 2014, de um relatório específico sobre o encarceramento feminino, com segunda edição lançada em 2018, com informações coletadas em junho de 2016.

${ }^{6}$ Mecanismo Estadual de Prevenção e Combate à Tortura de Pernambuco - MEPCT/PE. Relatório Temático 2016: Um olhar sobre o encarceramento feminino. Recife, 2016. CEPE. Companhia Editorial de Pernambuco.
} 
por associação ao tráfico porque seus filhos ou netos armazenavam drogas em suas casas; mulheres jovens que traficaram porque não encontraram oportunidade de emprego formal, ou não tiveram possibilidade de cumprir uma jornada de trabalho fora de casa por não terem com quem deixar os filhos; necessidade de arcar com as despesas de saúde, alimentação e educação das crianças e/ou demais membros da família, por terem sido abandonadas pelos seus companheiros ou, muito comumente, por seus maridos estarem presos. Não podemos esquecer ainda a realidade opressora das mulheres (das mais variadas idades) que são obrigadas a entrarem com drogas em unidades prisionais, como forma de pagamento das dívidas que seus companheiros/filhos/netos contraíram dentro da prisão.

Associamos estas trajetórias à vivência da subalternidade, que acaba se constituindo como uma experiência mais ou menos duradoura na história de vida de mulheres pobres, fazendo com que estas sejam alvo fácil do oportunismo de traficantes que, percebendo as fragilidades financeira, familiar e social destas mulheres, as recrutam para expandir o seu comércio ilícito. Por isso é importantíssimo uma análise menos dogmática por parte do poder judiciário e dos demais operadores do direito, tendo em vista que a aplicação da lei penal das drogas se caracteriza, segundo diversos estudos ${ }^{7}$, como sexista e misógina, pois penaliza duplamente a mulher que se envolve com o tráfico por necessidade e que, quando é presa (em um sistema penal historicamente pensado para prender homens), deixa os filhos desamparados afetiva e financeiramente, uma vez que o envolvimento com este ilícito penal reflete também a necessidade de obtenção de renda para a reprodução da família.

A presente pesquisa se caracterizou pelo seu caráter qualitativo e tomou como referência o estudo de caso do cárcere feminino em Pernambuco. Para chegar até às mulheres firmamos uma proposta de cooperação com o Patronato Penitenciário de Pernambuco, órgão de execução penal ligado à Secretaria Executiva de Justiça e Direitos Humanos, coordenado pela Secretaria de Desenvolvimento Social e Direitos Humanos, que exerce as funções de acompanhamento de processos, atenção psicossocial, pedagógica, e de inclusão produtiva de homens e mulheres reeducandos em regime aberto ou semiaberto ${ }^{8}$.

\footnotetext{
${ }^{7}$ Conferir: CAMPOS, Carmen Hein de. O Discurso Feminista Criminalizante no Brasil: limites e possibilidades. 1998. 180 f. Dissertação (Mestrado em Direito) - Universidade Federal de Santa Catarina. Curso de PósGraduação em Direito, Florianópolis, 1998.

OLIVEIRA, Mariana Paulo. O encarceramento feminino sob a égide da "guerra às drogas". 2017. $74 \mathrm{f}$. Trabalho de Conclusão de Curso - Instituto De Ciências Humanas E Sociais Psicologia, Universidade Federal Fluminense (UFF), Volta Redonda, 2017.

8 De acordo com a Lei de Execução Penal, a pena privativa de liberdade ocorrerá de forma progressiva, acontecendo a transferência do regime, quando o preso tiver cumprindo 1/6 da pena, a ser determinada pelo juiz. Os apenados em regime semiaberto ficam sujeitos "a trabalho em comum durante o período diurno, em colônia agrícola, industrial ou estabelecimento similar". Em regime aberto o condenado deverá, fora da unidade prisional e
} 
As mulheres que compõem esta pesquisa estão em cumprimento de pena, mas fora do cárcere, sendo identificadas e ouvidas durante os grupos mensais de acolhimento intitulados Diálogo entre Mulheres, que ocorrem mensalmente no Patronato. Neste artigo apresentaremos os dados coletados durante a realização de cinco grupos com as mulheres no ano de 2019, do mês de janeiro a maio, por terem se voltado a compreender as relações entre modos de vida e cotidiano de mulheres que vivenciaram o encarceramento. $O$ presente artigo está organizado em quatro seções. Na primeira buscamos refletir sobre o universo prisional feminino, o perfil das mulheres com passagem pelo cárcere e as questões de subalternidade ${ }^{9}$. A segunda seção refere-se à apresentação dos procedimentos metodológicos adotados para alcançar os objetivos. A terceira corresponde aos resultados e análises obtidos com o desenvolvimento desta pesquisa. Na última seção é apresentada a conclusão.

\section{FUNDAMENTAÇÃO TEÓRICA}

\section{Encarceramento de mulheres no Brasil}

Os dados do Levantamento Nacional de Informações Penitenciárias elaborados pelo Departamento Penitenciário Nacional - DEPEN indicam que "em torno de $58 \%$ das mulheres possuem vinculação penal por envolvimento com o tráfico de drogas não relacionado às grandes organizações criminosas" (BRASIL, 2014).

O relatório supracitado apresenta informações acerca do aprisionamento feminino no período compreendido entre os anos de 2000 a 2014, o qual revela que o crescimento da população prisional feminina foi de 579,4\%, o que representa em números absolutos uma população carcerária de mais de 37.800 mulheres. No mesmo período, o número de homens presos aumentou em 220\% (BRASIL, 2014).

Apesar de percentualmente o número de mulheres aprisionadas ser maior que o número de homens na mesma situação, estes representam em números absolutos a maior quantidade de pessoas presas no país; tal fato representa um desestímulo para a criação de novas unidades prisionais destinadas às mulheres (FARIAS, 2017). Pensando essa realidade brasileira, cabe ressaltar que o encarceramento de mulheres estabelece uma vinculação com a condição de classe e raça, haja vista as condições de exclusão iniciadas no processo de

"sem vigilância, trabalhar, permanecendo recolhido durante o período noturno e nos dias de folga" (BRASIL, 1984).

${ }^{9}$ A partir das contribuições de Edward Thompson; Gayatri Spivak e Jessé Souza. 
formação da sociedade brasileira, com o advento da escravidão e a violação dos direitos humanos de negros e negras ao longo da História.

Quando se trata do encarceramento de mulheres, a sociedade brasileira se revela androcêntrica, pois foi fundada de forma patriarcal, e o olhar que se estabelece é: à mulher que comete crimes cabe apenas desprezo, situação essa que contribui para o aumento do sofrimento de quem está em situação prisional. Desse modo, o abandono das mulheres encarceradas ocorre duas vezes, sendo a primeira pela omissão do Estado na função de cuidar das encarceradas, e a segunda pelo abandono afetivo praticado pelas famílias (FARIAS, 2017), uma vez que elas recebem um número muito menor de visitas, o que tem implicação direta na sua capacidade de sobrevivência dentro das prisões e, via de regra, são abandonadas pelos companheiros.

No estado de Pernambuco existem "duas unidades prisionais que são exclusivamente femininas: a Colônia Penal Feminina do Recife, situada no bairro do Engenho do Meio, zona oeste do Recife, e a Colônia Penal Feminina de Buíque, no sertão, situada a 296 km da capital” (BELO, 2009, p. 24).

A Colônia Penal Feminina do Recife (CPFR), também conhecida como Bom Pastor tinha este nome porque também foi administrada pelas Irmãs da Congregação Bom Pastor, compondo um "misto de presídio e penitenciária, abrigando presas tanto em regime fechado como em regime semiaberto" (BELO, 2009, p.27). Atualmente a CPFR abriga 670 reeducandas.

\section{As mulheres, a vivência da subalternidade e o cárcere no estado de Pernambuco}

No estado de Pernambuco, o perfil das mulheres encarceradas não difere do perfil dos demais estados brasileiros, de modo que as unidades prisionais contam com maioria de mulheres negras ou pardas, jovens, com baixa escolaridade, mães de mais de um filho, oriundas das camadas menos abastadas da sociedade e, em sua maioria, exerciam atividades informais de trabalho antes de adentrarem o sistema prisional (BRASIL, 2018).

No que se refere ao perfil de idade das mulheres em situação de cárcere em Pernambuco, os dados mostram que 51\% têm idade entre 18 e 34 anos, 44\% têm idade entre 35 e 60 anos, e apenas 5\% têm idade superior a estas (KOIKE, 2017).

Os crimes cometidos expõem a seletividade do Sistema de Justiça Criminal, apontando para o aparato punitivo do Estado voltado para repressão de determinados crimes 
(relacionados ao patrimônio e às drogas) e encarceramento de grupos sociais. De acordo com o Infopen - Mulheres (2018), a natureza dos crimes das pernambucanas corresponde a: homicídios (9\%); roubo (10\%); furto (15\%); latrocínio (1\%); tráfico (27\%); desarmamento (2\%) e outros (37\%). Para a maioria destas mulheres o envolvimento com tráfico de drogas ou furtos significou o envolvimento com o mundo do crime, pois são mínimos os casos de homicídio e outros tipos de crimes (IBIDEM, 2018).

Considerando esse contexto, podemos constatar que a trajetória de vida das mulheres em situação de privação de liberdade é seletiva, na medida em que "o narcotráfico e o consumo de drogas não são exclusivos das classes mais pobres, só que estas, pelo seu baixo poder de manobra frente ao Sistema de Justiça Criminal - SJC, serão mais punidas que as classes ricas" (POSADA, et al., p. 288).

Nessa perspectiva, dados da INFOPEN (2018) também destacam que a maioria das mulheres encarceradas pelo envolvimento com tráfico de drogas tem participação secundária no mundo do crime, exercendo transporte ou venda de drogas, e são, em muitos casos, usuárias. Além dessas situações mencionadas um ponto relevante nessa discussão é atenção para o envolvimento com o tráfico mediante vínculo afetivo com seus companheiros, pois se concretizam muitos casos de mulheres que são presas por levar drogas para seus companheiros que se encontram nas prisões.

Entretanto, essas situações vão além do envolvimento da relação estabelecida com seus companheiros, revela trajetórias de subalternidade, sendo essas mulheres, negras, mães, com baixa escolaridade (apresentando em sua maioria o ensino fundamental incompleto) e sobretudo apresentando limites relacionados ao acesso à renda e submetidas a precárias condições de trabalho.

Revela-se, portanto, uma relação direta com a possibilidade de agência destas mulheres, com a capacidade de assumirem lugar de fala ou exercício da autonomia com marcadores identitários tão desvalorizados em uma sociedade androcêntrica e estruturada por elementos colonialistas como a nossa.

Em alguma medida, o cárcere, como campo de análise, emerge dessas incertezas do percurso e sobre as trajetórias dessas mulheres frente às restrições no cotidiano. Isso rompe com os limites biográficos de suas falas e segmentos específicos para atingir o caráter coletivo da experiência, no sentido atribuído por Thompson (1987).

A Reflexão de Spivack (2012), no entanto, remete para a necessidade de compreender estas e outras mulheres a partir da sua condição de intérpretes, de seus espaços de 
significação e de "representação". Sivack (2012), ao analisar o silenciamento do sujeitos subalternos, faz uma distinção entre o conceito de "representação", sinônimo de "falar por" (vertretung), possuindo o sentido político de representar algo ou alguém, e o que chama de "representação", que está ligada à arte de encenação (darstellung), o que implica, em alguma medida, a agência destas mulheres sobre a experiência do cárcere, da forma como ela percebe, "encena" e sente essas condições.

A passagem pela prisão em muito pouco favorece a abertura desses espaços de "representação" às egressas, uma vez que o peso do encarceramento agrava ainda mais as vulnerabilidades físicas, psicológicas e sociais, elementos coercitivos para a/o egressa/egresso. Quando retornam à vida em sociedade, estes sujeitos são vítimas de imensas dificuldades sociais e psicológicas. Amplia-se uma espécie de não autoridade para o discurso, somada às condições econômicas baixas; redução das oportunidades (o que antes da passagem pelo cárcere eram mínimas, passam a ser quase inexistentes); "às dificuldades de inserção no mercado formal de trabalho, propiciam a reincidência delitiva, gerando ciclos viciosos de vitimização, violência, criminalidade, estigmatização e segregação social" (MINAS GERAIS, 2013, p. 18).

Cabe ao Estado propiciar a reinserção social das/os egressas/os, possibilitando assim aos sujeitos subalternos com passagem pelo cárcere condições mais favoráveis à sua ressocialização e agenciamento. Os direitos das/os apenados/as, egressas/egressos foram reafirmados através da regulamentação da Lei de Execução Penal (LEP). Partindo da LEP foi previsto o acompanhamento e ajuda pós-penitenciária por meio da assistência social, possibilitando as condições mínimas para que se mantenham em liberdade.

\section{PROCEDIMENTOS METODOLÓGICOS}

A presente pesquisa se caracteriza pela sua natureza qualitativa e tem inspiração na pesquisa-ação. Estabelecemos a pesquisa-ação como uma inspiração para esta pesquisa pelo caráter da relação entre a Universidade e a equipe técnica do Patronato Penitenciário de Pernambuco. Neste sentido, as ações de planejamento, execução e avaliação realizadas no âmbito desta pesquisa têm se encaminhado para um termo de cooperação técnica que permita, além da realização deste estudo, a possibilidade de a Universidade contribuir com a construção de melhores práticas de trabalho e instrumentais para diagnóstico sobre o universo prisional feminino em Pernambuco. 
Buscamos o Patronato Penitenciário de Pernambuco enquanto estratégia para chegar até às mulheres, com a compreensão de que são estas as nossas principais interlocutoras para desvendar os aspectos relacionados às vivências do pós-cárcere.

O Patronato é, em alguma medida, o primeiro órgão de contato com o Estado quando se põe o pé fora da prisão. O processo de remissão de pena, seja para o Regime Aberto (RA) e de Liberdade condicional (LC), tem o controle/acompanhamento pelo Patronato. Atualmente, ao saírem da prisão, há um prazo previsto de alguns dias para esta apresentação. Anteriormente, esta apresentação era imediata, sendo comum relato de pessoas que saíam da prisão sem nenhum dinheiro ou até mesmo vestuário completo e andavam quilômetros para chegar ao Órgão, uma vez que o não comparecimento implica na compreensão de que houve a intenção de fuga. Passam em média 200 pessoas por dia no Patronato, sendo que o maior fluxo ocorre às terças e quintas-feiras, por serem os dias de liberação de RA e LC.

Incumbido pela LEP no art. 79 da lei, o Patronato é responsável por: orientar os condenados à pena restritiva de direitos; fiscalizar o cumprimento das penas e de limitação de fim de semana; e colaborar na fiscalização do cumprimento das condições da suspensão e do livramento condicional. Sendo assim, as/os apenadas/os em cumprimento de regime aberto e liberdade condicional possuem a obrigatoriedade de apresentar-se ao Patronato mensalmente para o acompanhamento do processo de remissão de pena.

De acordo com o Patronato, em Pernambuco as mulheres com passagem pelo cárcere são atendidas pelo Patronato Penitenciário, que está organizado segundo polos de atendimento, sendo eles: Caruaru, Petrolina, Santa Cruz do Capibaribe e Recife. O polo do Recife atende cerca de 680 mulheres em processo de remissão de pena.

A composição de nossa amostra foi formada através de encontros mensais realizados no polo Recife, intitulados "Diálogos entre Mulheres", que têm como objetivo trabalhar temas relacionados ao empoderamento feminino, conscientização acerca do acesso a direitos e projeto de vida. Assumimos a organização do grupo junto com a equipe técnica do Patronato a partir de janeiro de 2019, e a partir de abril, até o presente momento, assumimos um protagonismo maior em relação ao desenvolvimento desta atividade.

Neste artigo apresentaremos os dados levantados no período de janeiro a maio de 2019, uma vez que estes primeiros encontros tiveram a intenção de levantar elementos relacionados à história de vida destas mulheres e os aspectos constitutivos de sua experiência no cotidiano do pós-cárcere. Os grupos com as mulheres foram realizados no auditório do Patronato e tiveram temáticas relacionadas aos objetivos desta pesquisa. Participaram de cada grupo em 
média 8 mulheres, e ainda a equipe do Patronato e da Universidade, totalizando aproximadamente 12 participantes por grupo. As mulheres que elegemos como principais interlocutoras para este artigo participaram de ao menos 4 dos 6 encontros. Relataremos as histórias de mulheres as quais nos referenciamos como Marias, chamando-as de Maria Sol, Maria Flor, Maria Lua, Maria das Letras e Maria das Mães.

É importante chamar atenção para a não obrigatoriedade de participação nestes encontros; as mulheres são convidadas à participação, e a estratégia de mobilização se deu através de contato telefônico e folhetos que eram entregues a elas no momento da coleta de assinatura. Outra estratégia utilizada, identificado o grupo com maior afinidade e interesse em participar dos encontros, foi a flexibilização da data para a coleta de assinatura das mulheres, sendo possível a assinatura nos dias de realização dos encontros. Estratégia muito importante, uma vez que o deslocamento gera custo. Elegemos alguns encontros como ancoragem para apresentar as trajetórias de vida das mulheres que compõem esta pesquisa, uma vez que não nos interessa neste trabalho a descrição dos encontros, mas compreender as relações entre modos de vida e cotidiano de mulheres que vivenciaram o encarceramento. A escolha dos meses que terão os encontros descritos se dá a partir do momento que estas experiências cotidianas nos foram reveladas de forma mais aprofundada pelas Marias, mas, de forma mais específica, nos voltamos para os meses de janeiro, fevereiro e maio.

Os grupos tiveram em média cerca de 3 h de duração e, para a realização de cada um destes encontros, tivemos em média duas reuniões anteriores com a equipe, para delineamento dos objetivos, estratégias de mobilização e metodologia a ser desenvolvida. A relatoria dos grupos foi realizada por um grupo de apoio aos círculos que participava das atividades na perspectiva de registro das falas, interações, reações, movimentos etc.

\section{RESULTADOS E ANÁLISES}

O Diálogo entre Mulheres foi-nos apresentado como uma estratégia criada pela equipe do Patronato para uma aproximação mais efetiva das mulheres egressas ao cárcere. Os grupos começaram a ser realizados em junho de 2018 e têm se constituído como o nosso lócus de aproximação com as mulheres. Conhecemo-nos durante os grupos, e isso permite uma aproximação fora deles, nos encontros nos corredores e em outros momentos de coleta da pesquisa. 
Conforme apresentamos anteriormente, participaram de cada grupo em média oito mulheres, além das equipes do Patronato e da Universidade. Em relação ao quantitativo de mulheres participando dos grupos, acreditamos que possa ter relação com o perfil das mulheres que estão sendo acompanhadas no período e com a época do ano. Algumas mulheres, ou a maior parte delas, não quer ter nenhum tipo de vínculo mais duradouro com o Órgão, vão assinar e/ou buscar algum tipo de atendimento nos setores de prestação de serviços e deixam rapidamente o local. No processo de mobilização ouvimos relatos de mulheres afirmando que quanto menos tempo permanecesse ali, menor a possibilidade de serem identificadas como "mulheres presas" ou de encontrar alguma outra "presa" que as identificassem.

Em relação à época do ano de realização dos encontros, percebemos que nos meses com comemorações públicas importantes no estado, como Carnaval e São João, a participação das mulheres entra em declínio, o que acontece desde os meses anteriores à festividade; no caso do Carnaval, por exemplo, o envolvimento acontece a partir de janeiro, período das prévias, em que as possibilidades de exercer alguma atividade com obtenção de ganho se ampliam significativamente.

Para apresentação deste momento e das questões que vinculam a trajetória destas mulheres à experiência da subalternidade vamos apresentar a história de algumas "Marias", as quais chamamos de Maria Sol, Maria Flor, Maria Lua, Maria das Letras e Maria das Mães. Os relatos foram colhidos nestes grupos que funcionaram como círculos de pesquisa. As Marias participaram conosco desde o primeiro grupo e nestes encontros/reencontros foram nos apresentando progressivamente as peças para compreender suas histórias de vida.

O primeiro encontro com as mulheres foi realizado em 31 de janeiro de 2019 e caracterizou-se como uma forma de estabelecer aproximação entre a equipe de pesquisa, a equipe técnica do Patronato e as mulheres em situação pós-cárcere. Foi realizada uma roda de conversa, que assumiu o formato de círculo de pesquisa, em que se utilizou a metodologia dos círculos restaurativos ${ }^{10}$ para o acolhimento das mulheres e de suas histórias.

Neste primeiro encontro apenas uma das mulheres falou sobre a passagem pelo cárcere, e o relato foi muito emocionado. Os relatos colhidos nos apresentam históricos de mulheres sofridas, em muitos casos abandonadas pelos companheiros, com sucessivas relações afetivas, que relatam uma vida de grande sobrecarga psicológica e social.

\footnotetext{
${ }^{10}$ Os círculos restaurativos compreendem uma abordagem colaborativa e pacificadora para resolução de conflitos.
} 
Formamos um círculo, e o objeto da palavra foi passado de pessoa para pessoa no sentido horário ${ }^{11}$. O objeto da palavra escolhido foi um porta-retratos de uma das pesquisadoras durante o período da gravidez; ela iniciou o círculo se apresentando e falando que em sua trajetória um marco que considerava importante partilhar era a experiência da maternidade.

A indicação para a atividade não era necessariamente que os relatos fossem sobre maternidade, era para ser relatado algum momento que consideravam importante. No entanto, todas as mulheres falaram sobre a maternidade, o que provavelmente teve influência do primeiro depoimento dado.

A perspectiva de partir da maternidade refere-se ao levantamento prévio do perfil das mulheres participantes do grupo, todas mães e/ou avós, e pensamos que este poderia ser um caminho para aproximação do cotidiano. Cabe destacar que apenas uma delas falou sobre o cárcere, as outras não nomearam, e quando o fizeram foi em relação à suposta motivação para algo que "fizeram de errado", "fiz o que fiz por causa dos meus filhos, para dar para eles do bom e do melhor".

O momento foi de muita emoção. Muitas das mulheres que participaram do grupo tinham vivenciado a maternidade muito cedo; os relatos, em sua maioria, foram experiências difíceis, de muito medo, sensação de abandono e carência (afetiva e material). Mulheres que se tornaram mães em um momento da vida em que se consideravam muito imaturas. Todas engravidaram na adolescência, com 14, 16 anos, sem noção das responsabilidades que iriam assumir.

Uma de nossas Marias (que chamaremos de Maria Sol) relata que ficou grávida pela primeira vez aos 14 anos, de um vizinho, não especificou a idade e nem a circunstância, relata uma experiência de muito medo. Começou o relato afirmando: "eu também tive medo, professora, muito medo", lembrou que na ocasião não fazia ideia de como os bebês nasciam, achava que estes nasciam pela boca e que foi uma vizinha que falou para ela que "eles nascem pelo mesmo lugar por onde são feitos". Maria Sol é uma mulher alegre, afetuosa, evangélica, com 54 anos, foi presa por tráfico e relata com muita dor o momento em que teve que voltar para a cadeia, anos depois de ter saído de lá. "Eu estava estendendo roupa no quintal com minha neta de 3 anos, os policiais chegaram, falaram o meu nome e disseram que

\footnotetext{
${ }^{11}$ Somente quem estava segurando o objeto tinha o direito de falar naquele momento, mas foi explicado ao grupo que todas tinham o direito de passar a vez, uma vez que nos círculos restaurativos ninguém pode sentir-se pressionado para contribuir.
} 
eu ia ter que ir com eles para a delegacia. No meu coração eu sabia que ia e não voltava, pedi só para chamar alguém para ficar com a minha neta. "12

As circunstâncias dessa volta para o cárcere ficam confusas sob a forte emoção que marcou o relato, mas cabe destaque que este movimento não aconteceu só com Maria Sol, mas com ao menos outras três mulheres que participaram do grupo. Acreditamos que seja devido ao envolvimento com mais de um processo, quando é solta pela conclusão de um, outro segue em andamento, e pode haver a solicitação de busca e apreensão.

Nossa outra Maria (que chamaremos de Maria Flor) começou a sua participação no grupo falando que sempre gostou de crianças, amava os filhos e principalmente os/as netos/as, mas que sempre detestou estar grávida. Nunca gostou de mostrar a barriga quando estava gestante, usava cinta até os seis meses e, muitas vezes, entrava em desarmonia com seu marido por conta disso.

Maria Flor trabalhava, na ocasião, um cemitério, frequentemente fazia referência a sua coragem para "encarar o trabalho", dizia não ter medo de pegar no pesado, "faço trabalho de homem". Adorava o trabalho no cemitério porque lá descobriu formas de ganhar renda extra através da pintura dos túmulos, do cuidado com o jardim e da "maquiagem dos defuntos".

Constantemente afirmava que o dinheiro que conseguia era para dar à neta. A filha é dependente química de crack e deu a menina para ela criar. $\mathrm{O}$ marido e o filho estão presos. Ela visita o filho, mas não o marido, pois, segundo ela, "não quer mais nada com esse marido", porque não pretende voltar para a cadeia.

O marido foi preso por tráfico, "meu filho não é traficante, é assaltante", e isto é tido por ela como um elemento em alguma medida valorativo, o que talvez tenha referência ao fato de que não era dependente químico como a filha. Relatou com grande entusiasmo o fato de que o filho recentemente havia passado por um curso de doces e salgados, "aprendeu a fazer tudo de salgado, quando ele sair tem que mexer com isso, para conseguir viver aqui fora".

No segundo encontro foi apresentado um vídeo disparador ${ }^{13}$, o Filme de Teta, que apresenta a vida real de Teta Gomes, no qual o enredo do documentário se volta para o tempo do pós-cárcere. O documentário acompanha a rotina de Teta, uma recifense que acaba de passar por uma mudança em sua vida. Após dez anos cumprindo pena na Colônia Penal

\footnotetext{
${ }^{12}$ Maria Sol terminou o processo de remissão de pena em abril e ainda permaneceu indo alguns meses e participando dos grupos mensais. No mês de conclusão foi se despedir do grupo e, muito emocionada, disse que não queria parar de participar.
}

${ }^{13}$ O Filme de Teta, um documentário com direção e roteiro de Raquel do Monte, do ano de 2013.

Conferir: <https://youtu.be/A-Tkk9YRb40>. 
Feminina Bom Pastor, sai da prisão, mas todos os domingos volta ao local que a abrigou por anos, em visita a sua companheira, na ocasião ainda presa.

O documentário nos apresenta uma reflexão sobre o tempo marcado pelo cárcere, sendo dividido em três partes. A parte utilizada como disparador do encontro foi a segunda, por se voltar para os desafios de se integrar à sociedade e a um novo cotidiano após a prisão, as dificuldades socioeconômicas que permeiam a vida das mulheres, agravadas pela vivência do cárcere.

O tema do encontro foi Histórias de Vida - refletindo o cotidiano pós-cárcere. Tivemos a intenção de compreender os movimentos da vida destas mulheres. A questão dos diferentes papéis sociais vivenciados (ser mãe, companheira, trabalhadora, vizinha, cidadã etc.) e o uso do tempo.

Se no primeiro encontro apenas uma delas fez menção ao tempo do cárcere, neste segundo momento muitas delas o fizeram. Mesmo que Teta não fosse um nome conhecido para muitas delas, o cenário e o cotidiano apresentados no documentário geraram forte identificação. Teta, durante o trecho escolhido para a exibição, mostra o seu cotidiano em um domingo, preparando as sacolas que irá levar para a prisão. Moradora de uma palafita, em uma área de ocupação urbana, transita por vielas e becos do centro para pegar o ônibus que a levará à Colônia Penal Feminina Bom Pastor, localizada no bairro da Iputinga, na cidade do Recife ${ }^{14}$.

Quando o cenário muda, e Teta desce do ônibus e caminha até a fila para passar pela triagem e revista que a levará à prisão, iniciaram-se as manifestações do grupo. Ao assistirem o filme elas fizeram muitos comentários, identificando o presídio e pessoas conhecidas que são mostradas na fila, no pátio, nas celas. Narraram também as dificuldades vivenciadas, as ansiedades (que muitas vezes resultavam em desentendimentos e no "castigo para acalmar") ${ }^{15}$, desprezo pelo poder público, a falta de humanidade de alguns profissionais, as discriminações sofridas, os maus-tratos. Segundo uma delas, a cadeia não é lugar de gente, "tratam a gente igual a bicho, um lugar que merece ser esquecido". Era visível nos olhos o sofrimento e a humilhação a que elas foram submetidas.

\footnotetext{
${ }^{14}$ No estado de PE existem as Colônias Penais Femininas de Abreu e Lima (CPFAL), Buíque (CPFB) e Recife (CPFR), e há também o Hospital de Custódia e Tratamento (HCTP) que abriga pessoas com problemas mentais que cometeram delitos e é unidade mista. A CPFB e a CPFR são unidades exclusivamente femininas, enquanto as demais são mistas.

${ }^{15}$ É recorrente nas falas das egressas a adoção do castigo ou solitária como elemento de disciplina durante o cárcere, para conter e punir comportamentos excessivos.
} 
Como esperávamos, as mulheres se sentiram motivadas a falar sobre o tempo de vivência no cárcere e passaram a tecer comentários sobre o tempo que estiveram encarceradas. O filme mostra que Teta, mesmo fora do cárcere, mantém um vínculo afetivo com aquele espaço. A companheira está presa, e o fato de trabalhar no fórum facilita que ofereça ajuda para o acompanhamento dos processos das pessoas que aguardam a desejada liberdade. A angústia relacionada ao desconhecimento do andamento dos processos foi algo relatado de forma unânime pelas mulheres que participaram dos grupos.

Curiosamente, apenas uma delas não se sentiu confortável em compartilhar suas recordações, a mesma que no primeiro encontro havia sido a única a falar sobre o cárcere. Disse não querer mais falar sobre isso, pois alegou que sofreu muito e isso tudo lhe causava mal, relatou também que luta todos os dias para apagar esse passado. Converteu-se à Testemunha de Jeová na prisão, fala o tempo todo em Deus, atribui a Ele o que chama de livramento, e contou, chorando, que aproveita todos os instantes da sua vida para se dedicar a sua família, seus amigos, para recuperar os anos perdidos.

A conversão à Testemunha de Jeová da egressa tem relação com o amplo espaço alcançado pelas religiões neopentecostais no Brasil, e o alcance predominante sobre a ralé não pode ser encarado superficialmente, "remontam à totalidade do modo de vida dessa classe social". O cotidiano dos sujeitos da ralé desde a sua infância é marcado pela violação e negação dos direitos, condicionando a uma precarização da vida e formação dessa classe social, desprovida de valores morais e educacionais, necessários para socialização com as classes dominantes.

As igrejas neopentecostais atuam na perspectiva de excluir os marcadores sociais que remontam às origens precarizadas desses indivíduos. Oferecendo aos seus "crentes delinquentes" uma estratégia para manter o controle sobre seus impulsos, atribuindo às forças externas aos indivíduos as razões pelas práticas de delinquência. A via religiosa atua para auxiliar no controle dos impulsos. As ações que os levaram ao cárcere serão sempre atribuídas ao mal, para que esses indivíduos possam manter a esperança viva para validarem suas vidas e consequentemente não voltar à criminalidade, sendo a fé desses sujeitos o combustível para manterem viva a esperança. Nas religiões de caráter salvador os fiéis são conduzidos a avaliarem o passado e a desprezarem "os valores mundanos" (SOUZA, 2009).

O terceiro momento que utilizaremos como ancoragem para a apresentação dos relatos foi em comemoração ao Dia Internacional da Mulher. Utilizamos novamente um vídeo como disparador, com o objetivo de incentivá-las a falar sobre os desafios de ser mulher em nossa 
sociedade. O vídeo utilizado foi Acorda Raimundo, acorda! do ano de 1991, que discute sobre a inversão dos papéis sociais de homens e mulheres. O objetivo foi observar como as mulheres se percebiam, e se identificavam diferenças nos papéis sociais vivenciados.

As mulheres, no início da discussão, achavam que o homem do vídeo era muito "pamonha", adjetivo figurado para a ausência dos caracteres esperados por elas do que é ser homem na sociedade. Expressaram dificuldade de apreender papeis sociais fluidos entre homens e mulheres, reforçando em alguns comentários que o espaço doméstico é feminino, e o público é masculino "[...], mas se está em casa ele tem que pelo menos lavar os pratos" (Maria Flor), "meu menino faz até comida para eles [...] a mulher dele também trabalha, mas eu acho errado, para mim ela se aproveita" (Maria Lua). Chamaram atenção para relações de subserviências durante o casamento. Chamou a nossa atenção que, antes de passarem pela situação do cárcere, não tinham escutado falar sobre o Dia Internacional das Mulheres, pois até então era um dia como outro qualquer, apesar de comentarem que esperavam serem "cuidadas" (Maria Sol), o que remetia a não serem responsabilizadas pelas atividades domésticas naquele dia. Somente durante o cárcere é que tiveram contato com as discussões sobre os direitos das mulheres.

Neste dia, as Marias estabeleceram conversas com algumas integrantes do grupo antes do filme, e após este se sentiram à vontade para externarem aspectos de suas histórias. Maria Flor narrou que começou a usar maconha aos 9 anos de idade, por influência de amigas. Casou com 15 anos, teve duas filhas e um filho, seu marido era violento e lhe batia muito, mesmo assim, "com a ignorância dele a gente conviveu 20 anos".

Maria Lua é mais reservada, uma senhora de 76 anos, calada, com ar de cansada, aparência sofrida, e silenciosa. Participa dos grupos, chega cedo, fala pouco. Abriu-se para uma das pesquisadoras. Natural de Vitória de Santo Antão (Mesorregião da Mata Pernambucana), trabalhou durante muito tempo como empregada doméstica (ressalta que em uma das casas onde trabalhou por mais de dez anos como copeira haviam mais de dez funcionários/as). Tem seis filhos, sendo três adotados. Atualmente, mora com um dos netos em um bairro periférico e com a esposa dele que está grávida, mais um bisneto. Maria Lua tem três bisnetos. Uma de suas filhas ficou viúva recentemente e é a que mais faz companhia, já que o neto trabalha muito como técnico de informática. Tem outro neto que estuda computação em uma faculdade e trabalha; ela fala com orgulho que ele é estudioso e do quanto se esforça para pagar a faculdade. 
Cumpriu pena durante três anos na Colônia Prisional Feminina de Abreu e Lima (CPFAL) por tráfico de drogas, sinaliza que por questão de saúde o juiz concedeu prisão domiciliar, e que utilizou tornozeleira durante um tempo. Lembra que sentia muita vergonha, porque tinha que fazer fisioterapia todos os dias pelo problema no joelho. É católica e relatou que frequenta a igreja sempre que dá. Sinaliza que pela proximidade com os netos e bisnetos acha que as meninas deveriam cuidar mais de casa. Não gosta do compromisso de ter que ir assinar, mas é melhor que tornozeleira, às vezes vai com a filha ao Patronato. Algumas das amizades que fez no tempo de cárcere seguem aqui fora, principalmente com algumas outras mulheres que frequentam o grupo.

O grupo se concluiu em um clima de festividade, com o sorteio de brindes e a promessa de comparecimento no próximo encontro. Segundo a análise de Maria Sol, as mulheres não estão vindo por vergonha, vir para um grupo de presas seria uma forma de exposição. Refletimos sobre isso de forma conjunta.

O encontro correspondente ao mês de abril foi realizado no dia 25 e teve como tema: Oficina: Boneca Abayomi, realizada por uma das integrantes do grupo Loucas de pedra Lilás ${ }^{16}$, que se auto intitula feminista, negra e artivista $^{17}$ dos direitos das mulheres e da educação. $O$ auditório foi ornamentado, livros de poetas feministas negras foram dispostas sobre as mesas, músicas tribais tomaram conta do ambiente. A boneca Abayomi foi disposta no centro da sala, a artivista iniciou a oficina, lendo e interpretando uma poesia que tratava do movimento de libertação de uma mulher.

A poesia foi utilizada como uma espécie de "ponte", com uma dinâmica de interação com as mulheres com intuito de fazê-las partilhar os seus medos e sonhos. A indicação foi para que se apresentassem e falassem bem alto, "em alto e bom som", sobre quem eram e o que gostavam de fazer. Nesse momento houve ampla participação das mulheres, elas se divertiram falando sobre seus sonhos, o que em alguns momentos percebemos como espécie de fugas, de resistências em seus cotidianos. "Sou Maria e gosto de ficar à toa" disse uma delas, grito que foi procedido por uma gargalhada. "Ficar à toa, quem me dera", disse ela, "logo ela que trabalha feito uma condenada". Após a conclusão da dinâmica, a artivista deu início à história da boneca, da mulher negra, das saudades, das resistências. Destacou o passo a passo para a confecção da boneca por meio de retalhos de tecidos de variadas cores e texturas, trazidos consigo e o processo de construção da história de mulheres negras, da

\footnotetext{
${ }^{16}$ O grupo Loucas de Pedra Lilás, composto unicamente por mulheres, trata-se de um grupo de teatro feminista.

${ }^{17}$ Artivista - Termo utilizado por militantes e ativistas que utilizam as diferentes formas de arte como mecanismo de ativismo político, ecológico, social ou espiritual.
} 
maternidade e da submissão. Enquanto narrava a história da Abayomi, ressaltava a importância do empoderamento feminino e do movimento negro para ajudar a ter consciência de quem elas são.

Os acontecimentos pós-cárcere vão sendo colocados como justificativa e sendo apresentados a cada acréscimo da confiança. Ao longo da realização da oficina, duas mulheres compartilharam sobre os desafios que viviam e os delitos cometidos. Uma delas foi presa por estelionato, e outra por homicídio. Apresentaremos o relato da primeira, por atender aos critérios de participação descritos na metodologia. Participou de ao menos quatro dos seis encontros. Iremos chamá-la de Maria das Letras.

A passagem dela pelo cárcere foi breve, ficou em regime fechado por dois meses e cumpriu a pena de um ano e três meses em casa usando a tornozeleira eletrônica, e por isso a sua fala é deslegitimada a todo o tempo pelo grupo, o que consideramos bastante significativo, devido a algo que fomos percebendo com o tempo da pesquisa, nas relações e interações estabelecidas com elas e entre elas. Há uma hierarquia em relação à autoridade para se remeter à experiência do cárcere, o que tem relação com o perfil socioeconômico, com o tipo de crime cometido, com a unidade ou ala em que se ficou presa. Uma das mulheres egressas ao cárcere e que participa do grupo de forma esporádica foi presa por assalto a banco, percebemos que isso Ihe atribui um status significativo, por ser este um "crime de inteligência e coragem" geralmente cometido por homens.

Maria das Letras relatou ter cometido o crime de estelionato quando ainda tinha 32 anos, casada, com três filhos pequenos, marido desempregado e a tia doente que estava sob seus cuidados em sua casa. Após o falecimento da tia, recebeu por três anos a pensão, no valor de um salário mínimo à época. Passados 27 anos do delito, o crime foi descoberto e sofreu condenação, embora a família tenha pago o valor de cinco mil reais, correspondente à pensão recebida por três anos. Ela passou cerca de dois meses na Colônia Penal Feminina Bom Pastor.

Ela tem um perfil bastante distinto das outras mulheres com as quais estabelecemos contato, fez graduação e mestrado e, "como professora e mestra", prestava serviço na escola da Colônia Penal. Narra ainda que recebia visitas de seu irmão, médico, que acompanhava a sua situação de saúde, por ter doenças como diabetes, pressão alta, asma e outras. Não aceitava receber visitas do marido, por questões emocionais e de saúde dela e do companheiro. Expressou que o período do cárcere representou uma ruptura com outros momentos de sua vida. 
Maria das Letras relatou que nunca na vida imaginou que pudesse se ver em uma prisão, mas quando se viu, criou formas de autoproteção, agiu segundo orientações de familiares, "eu não aceitava ou reivindicava nada a ninguém da penitenciária, desde as detentas até os profissionais".

Foi pouco a pouco relatando o seu estranhamento com o que viu e vivenciou neste tempo da prisão, como o fato de que dividia cela com duas mulheres acusadas de assassinato que, segundo ela, eram "cultas e de classe média". Em determinado momento disse que os/as agentes e demais profissionais que atuavam na cadeia eram muito educados, o que teve forte reação do grupo, "só se foi com você minha filha", "tu não sabe o que é cadeia, táva de férias na prisão".

Maria das Letras esporadicamente ainda comparece ao grupo; no último encontro que tivemos, em março de 2020, demonstrou interesse em contribuir com a equipe na organização dos encontros, trabalhar com literatura, alfabetização ou ensinar artesanato.

O último encontro que descreveremos como ancoragem para as histórias das mulheres foi realizado no mês de maio de 2018 e abordou a temática da maternidade e do autocuidado. O encontrou teve início com a apresentação do superintendente do Patronato Penitenciário de Pernambuco e a coordenadora psicossocial e outros profissionais de diversos setores desejando boas vindas e informando sobre os cursos e serviços oferecidos no órgão ${ }^{18}$. Neste oitavo encontro contamos com a presença de 11 mulheres, além das equipes do patronato e do Observatório da Família e estudantes voluntários do Centro Universitário Brasileiro (UNIBRA).

Com o objetivo de trabalhar a maternidade e o autocuidado após o círculo de pesquisa, foram ofertadas atividades de massoterapia, maquiagem e design de sobrancelhas.

Por demanda do Patronato, o encontro deveria ser pensado também com caráter comemorativo em alusão ao mês das mães e promovendo momentos de lazer a essas mulheres. Os relatos que se seguem ocorreram no decorrer da realização da oficina, e/ou enquanto recebiam os cuidados do/as aluno/as em alguma das atividades.

Uma das 11 mulheres levou sua neta de 11 meses de idade ${ }^{19}$ para a atividade, relatando que resolveu assumir a criança e agora é a mãe dela. Iremos chamá-la de Maria das Mães. Em seu relato, apresentou uma preocupação muito grande com a filha, que, "apesar de ser boa

\footnotetext{
${ }^{18}$ Ocorrendo comumente a presença do superintendente e dos funcionários do Patronato na abertura dos grupos, para darem boas-vindas as mulheres que alcançaram a progressão da pena, tendo em vista que o Diálogos se constitui como um grupo aberto, a formalidade apresentada por vezes quebra a interação do grupo.

${ }^{19}$ A neta de Maria das Mães tem acompanhado os grupos mensais desde os seus primeiros meses de vida. Na realização dos grupos presenciamos o desenvolvimento das primeiras habilidades, seus primeiros passos e suas primeiras palavras.
} 
mãe", tem muitos filhos, na ocasião eram 7 no total. Depois desta, com 11 meses na ocasião, havia nascido um outro neto, com poucos dias, e sua filha ainda estava de resguardo e apresentava um quadro de depressão pós-parto.

Maria da Mães está respondendo ao crime de associação ao tráfico, relata ter cumprido cinco anos em regime fechado e agora cumpre em liberdade, tendo que assinar até 2025. Ela relata a circunstância da prisão e de seu envolvimento através do empréstimo de seu telefone celular para realização de duas ligações, que posteriormente descobriu estarem vinculadas às atividades do tráfico. Detida em 2013, cumpriu dois anos e desde cinco de julho de 2015 está em liberdade. Descreve que os dois anos presa foram os piores momentos de sua vida, mas afirma que se apoiou na fé e que tem " um Deus poderoso".

Ao encerramento do grupo, algumas egressas relataram que nunca haviam recebido "toques" (referindo-se a massagem) ou qualquer tipo de cuidado com a estética. E em alguns relatos expuseram que não se consideravam "dignas" de estarem recebendo aqueles cuidados. Além do mais, a cada grupo a participação das mulheres era bastante retraída, passando a participar das atividades com apoio dos membros da equipe. Durante a realização dos grupos e mediante as atividades propostas, algumas das mulheres não costumavam participar, relatavam a questão da religiosidade, que as impedia.

As histórias de vida remetem a trajetórias de subalternidades que se materializam através de uma grande mobilidade urbana, devido à violação do direito à moradia (mudam-se para bairros onde podem pagar o aluguel), baixa escolaridade, violência doméstica, empregos extremamente precários (quase a totalidade delas tem um histórico de inserção desde a infância em trabalhos domésticos). O que as vinculam, de acordo com Souza (2009), às mulheres da ralé, que constituem a categoria elementar de trabalhadores, submetidas "à elevada depreciação social do trabalho braçal e despojadas de habilidades comportamentais e cognitivas mais valorizadas”. As mulheres que compõem o universo desta pesquisa para geração de renda e provimento das condições materiais de reprodução de suas famílias atuaram em trabalhos que exigiam pouca ou nenhuma qualificação e, por isso, tiveram pouco ou nenhum reconhecimento, são mulheres que desde a infância/adolescência estiveram envolvidas com o trabalho doméstico, informal, sazonal.

Segundo Spivak (2014), as mulheres constituem a categoria do grupo mais subalterno da sociedade, sendo o sujeito subalterno feminino jogado na obscuridade e possuindo forte marcador social atrelado às diferenças de raça e classe. Essas mulheres da "ralé" compõem o 
subproletariado urbano, apresentando a negação e a exploração como constituintes das relações patriarcais estabelecidas nos ambientes domésticos.

Percebemos durante a realização dos encontros e nas interações que estabelecemos durante esta pesquisa, que o tempo do cárcere se configura como um marco, muito doloroso, que se estabelece sobre trajetórias de vivência da subalternidade de forma muito acentuada e significativa. As "Marias" que apresentamos a partir de suas narrativas neste artigo ecoam a trajetória de quase todas as outras mulheres que encontramos nestes quase três anos de pesquisa, também Marias, que tal qual os Severinos de João Cabral de Melo Neto, são "iguais em tudo na vida". Alijadas de fala, de poder, de capacidade de ação. Moradoras das periferias das cidades, provenientes de famílias e relações violentas, produtoras de outras relações violentas, mulheres que povoam as cidades e os direitos de modo periférico e clandestino.

\section{CONSIDERAÇÕES FINAIS}

De modo geral, os resultados obtidos apontam que há uma reprodução geracional de trajetórias subalternas na história de vida destas mulheres, agravada pela vivência do/no cárcere, com incidência sobre as suas subjetividades, estabelecimento de relações com as pessoas, bens e serviços.

O cárcere e o encarceramento constituem um fenômeno essencialmente vinculado aos elementos constitutivos da subalternidade. Do alijamento de fala, da desigual distribuição de poder. A mulher encarcerada é fisicamente apartada da sociedade, separada e punida pela forma como respondeu às limitações de sua experiência como sujeito histórico. Ao sair da prisão, carrega-a como marca e estigma e é muitas vezes novamente apartada e punida pela sociedade e instituições.

Os estudos sobre o encarceramento precisam ampliar os espaços de "representação" destes sujeitos, de atribuição de significado e sentido para as suas experiências. É preciso tornar o encarceramento em massa cada vez mais público, como forma de romper com a invisibilidade que configura a condição de subalternidade das mulheres encarceradas.

As trajetórias das mulheres pós-cárcere configuram realidade marcada pela negação e violação de direitos fundamentais e básicos para garantia de uma vida digna. Os dados da pesquisa indicam que as mulheres em situação pós-cárcere têm classe e cor específica, ou seja, são provenientes de contextos subalternos, em sua maioria, são mulheres negras, 
periféricas, mães e/ou avós, com inserção precária ao mercado de trabalho e com sérias restrições no que diz respeito ao acesso a direitos.

Com a impossibilidade de inserção ao mercado de trabalho, imposta pelo perfil e estigma vivenciado por estas mulheres, o cotidiano delas é caracterizado pela realização das atividades domésticas e reprodutivas. Ao saírem da prisão, se tornam muitas vezes responsáveis pelo cuidado de outros membros da família em situação de vulnerabilidade, geralmente netos/as, o que amplia as dificuldades relacionadas para o acesso à renda. Em sua maioria realizam atividades de trabalho informal, haja vista o desafio de reinserção mercado de trabalho.

As mulheres revelaram o arrependimento e a culpa pela inserção no mundo do crime, o que é manifesto através de um vínculo muito significativo com inserção em algum tipo de religião, sinalizando a vinculação de algumas das mulheres com a religião como apoio no processo de ressocialização.

A pesquisa também revela a importância do acolhimento familiar para o processo de ressocialização das mulheres com relação direta sobre a perspectiva ou não de reincidência de delitos, constituindo-se como elementos fundamentais para o processo de reinserção social.

\section{REFERÊNCIAS}

AGUIRRE, C. Cárcere e sociedade na América Latina. 1800 - 1940. In: Maia, C. N. et al. (Org.) História das prisões no Brasil. Rio de Janeiro: Rocco, 2009. V. 1, p. 38-39.

ANGOTTI, Bruna. A criação dos presídios femininos no Brasil nas décadas de 1930-1940. 2012. Disponível em: https://goo.gl/8Q4aTC. Acesso em: 13/03/2018.

ANGOTTI, Bruna. Entre as leis da ciência; do estado e de Deus: o surgimento dos presídios femininos no Brasil. 1 ed. - São Paulo: IBCCRIM, 2012.

ARTUR, Angela Teixeira. As origens do "Presídio de Mulheres" do Estado de São Paulo. 2011. 126 f. Dissertação (Mestrado em História) - Programa de Pós-Graduação em História Social, Faculdade de Filosofia, Letras e Ciências Humanas, Universidade de São Paulo, 2011. Disponível em: https://goo.gl/erLKJg. Acesso em: 13/03/2018.

BELO, Charisma Cristina Alves Tomé. Economia criativa no cárcere feminino: um laboratório para produção de material didático (vídeo) em EAD. Dissertação (Mestrado profissional em Tecnologia e Gestão em Educação a Distância) Universidade Federal Rural de Pernambuco, Unidade Acadêmica de Educação a Distancia e Tecnologia, Recife, 2014.. 
BORGES, Ivna. Mães encarceradas: onde estão seus filhos? Um estudo de caso em uma unidade prisional de Recife - PE. Viçosa: UFV, 2003

BRASIL. Constituição da República Federativa do Brasil, 1988.

BRASIL. Código Penal. Decreto Lei n² 2.848, de 07 de dezembro de 1940.

BRASIL. Código de Processo Penal. Decreto Lei n 3.689, de 3 de outubro de 1941.

BRASIL. LEP - Lei de Execução Penal - Lei 7210/1984.

BRASIL. Ministério da Justiça. Levantamento Nacional de Informações Penitenciarias -Infopen. 2014ㄹ. Disponível em: https://goo.gl/mCK6n9. Acesso em: 13/03/2018.

BRASIL. Ministério da Justiça. Levantamento Nacional de Informações Penitenciárias -Infopen Mulheres. 2014b. Disponível em: <https://goo.gl/thRa3w Acesso em: 13/03/2018.

BRASIL. Ministério da Justiça. Levantamento nacional de informações penitenciárias - Infopen mulheres, 2ed. Disponível em: < http://depen.gov.br/DEPEN/depen/sisdepen/infopen-mulheres/infopenmulheres_arte_0703-18.pdf >. Acesso em : 11/07/2018.

CERNEKA, Heidi Ann. Homens que mestruam: considerações acerca do sistema prisional às especificidades da mulher. Veredas do Direito: Direito Ambiental e Desenvolvimento, Belo Horizonte, v.6, n. 11, p. 61-78, 2009.

CERVO, Amado Luiz; BERVIAN, Pedro Alvino; SILVA, Roberdo da. Metodologia científica -6. Ed.- São Paulo: Pearson Prentice Hall, 2007.

CHARNOUX, Ofélia Maria Guazzelli. Metodologia: processo de produção, registro e relato de conhecimento. 3르. Ed. São Paulo: DVS, 2006.

COLARES, Leni Beatriz Correia; CHIES, Luiz Antônio Bogo. Mulheres nas so(m)bras: invisibilidade, reciclagem e dominação viril em presídios masculinamente mistos. Estudos Feministas, Florianópolis, v. 18, n. 2, p. 407-423, 2010.

CUNHA, Fernanda. Além das grades: uma do sistema prisional feminino no Brasil. Disponível em: http://carceraria.org.br/alem-das-grades-uma-leitura-do-sistema-prisionalfeminino-no-brasil.html. Acesso em: 13/03/2018.

DOTTI, René Ariel. A crise do sistema penitenciário. Artigos de Direito, 2003. Disponivel em: HTTP://www.egov.ufsc.br/portal/sites/default/files/anexos/12441-12442-1PB.pdf. Acessado em: 25/03/2018.

FERREIRA, Simone de Figueiredo. A diferenciação entre adolescente que cumpre medida socioeducativa e a mulher que cumpre pena no sistema penitenciário. In: Mecanismo estadual de prevenção e combate à tortura: relatório temático: um olhar sobre o encarceramento feminino. Recife: CEPE, 2017. 
FARIAS, Emili Caroline Cota de Jesus. Maternidade no cárcere. Revista Jus Navigandi, ISSN 1518-4862, Teresina, ano 23, n. 5636, 8 mar. 2018. Disponível em: https://jus.com.br/artigos/62457. Acesso em: 19/03/2018.

GODOI, Rafael. Ao redor e através da prisão: cartografias do depositivo carcerário contemporâneo. Dissertação apresentada ao Programa de Pós-Graduação de Sociologia da Universidade Faculdade de Filosofia, Letras e Ciências Humanas da Universidade de São Paulo - USP. São Paulo, 2010. Disponível em:Http//:www.teses.usp.br/teses/disponiveis/8/8132/.../2010 RafaelGodoi.pdf. Acesso em: $13 / 03 / 2018$

GRECO, Rogério. Direitos Humanos, sistema prisional e alternativas à privação de liberdade. São Paulo: Saraiva, 2011.

KOIKE, Maria Lygia. Maternidade e Gravidez no sistema prisional de Pernambuco. In: In: Mecanismo estadual de prevenção e combate à tortura: relatório temático: um olhar sobre o encarceramento feminino. Recife: CEPE, 2017.

LAKATOS, Eva Maria. MARCONI, Marina de Andrade. Metodologia cientifica. - 7ed. São Paulo: Atlas, 2017.

LEMGRUBER, Julita [e] PAIVA, Anabela. (2010), A dona das chaves: Uma mulher no comando das prisões do Rio de Janeiro. Rio de Janeiro, Editora Record.

MELLO, Daniela Canazaro de. A prisão feminina: gravidez e maternidade, um estudo da realidade em Porto Alegre - RS/Brasil e Lisboa/Portugal. Tese de Doutorado - Programa de Pós-Graduação em Ciências Criminais, Faculdade de Direito, Universidade Católica do Rio Grande do Sul. Porto Alegre, 2014.

MONTEIRO, Marília. A saúde da mulher privada de liberdade. In: Mecanismo estadual de prevenção e combate à tortura: relatório temático: um olhar sobre o encarceramento feminino. Recife: CEPE, 2017.

MOURA, Danieli Veleda. A crise do Sistema Carcerário Brasileiro e sua consequência na ressocialização do apenado. JV Jus Vigilantibus, S/D. Disponível em: HTTP://jusvi.com/artigos/40365. Acessado em: 11/10/2017.

NE 10: Blog de Jamildo. Contrariando Pedro Eurico, Promotor defende a desativação do Complexo do Curado. Acesso em: 15 de julho de 2019. Disponível em: https://blogs.ne10.uol.com.br/jamildo/2017/07/19/contrariando-pedro-eurico-promotor-defendea-desativacao-do-complexo-do-curado/ .

NEGROMONTE, Pércio. Um breve histórico da prisão de mulheres. In: Mecanismo estadual de prevenção e combate à tortura: relatório temático: um olhar sobre o encarceramento feminino. Recife: CEPE, 2017. 
OLIVEIRA, Érika Patrícia Teixeira de. Mulheres em conflito com a lei: representações sociais, identidades de gênero e letramento. Disponível em: http://www.ple.uem.br/defesas/pdf/eptoliveira.pdf. Acesso em: 13/03/2018.

PAZ, Carlos Eduardo Barbosa ...et al. Habeas Corpus(143.641): Todas as mulheres submetidas à prisão cautelar no sistema penitenciário nacional, que ostentem a condição de gestantes, de puérperas ou de mães com crianças até 12 anos de idade sob sua responsabilidade, e das próprias crianças. Defensoria pública da união, Brasília, 2017. Disponível em:

www.stf.jus.br/portal/processo/verProcessoAndamento.asp? numero $=143641$ \&classe $=\mathrm{H}$ C\&origem=AP\&recurso=0\&tipoJulgamentocias.Acessasdo em: 19/03/2018

POSADA, Rafael Andrés Urrego. Mulher, raça e encarceramento massivo no Brasil. In: Sistema Prisional: teoria e pesquisa. Org: Fernando Fidalgo e Nara Fidalgo. Belo Horizonte, Editora UFMG, 2017.

SANTA CRUZ, Mariana; KOIKE, Maria Lygia; NEGROMONTE, Pércio; FIGUEIREDO, Simone. Das visitas ao sistema prisional. In: Relatório anual do mecanismo estadual de prevenção e combate à tortura de Pernambuco. Recife: CEPE, 2017.

SANTOS, Jahyra Helena Patrícia dos; SANTOS, Ivanna. Pequeno dos. Prisões: um aporte sobre a origem do encarceramento feminino no Brasil. Disponível em: http://www.publicadireito.com.br/artigos/?cod=c76fe1d8e0846243. Acesso em: 13/03/2018.

SANTOS, dos Charisma Cristina Alves Tomé. Um olhar sobre a colônia penal feminina do Recife: dinâmica e compreensão do perfil da mulher no cárcere. Monografia (Especialização) - Faculdade Integrada do Recife, Recife, 2009.

SILVA, Felipe Henrique Oliveira da. Gênero, maternidade, cotidiano e o cárcere. 2019. $50 \mathrm{fls}$. (Relatório Final do Programa de Iniciação Científica) - Programa de Iniciação Científica, Universidade Federal Rural de Pernambuco, 2019.

SOUZA, Jessé. Ralé Brasileira: Quem é e como vive. 1. ed. Belo Horizonte: Editora UFMG, 2009. Disponível em: http://flacso.redelivre.org.br/files/2014/10/1143.pdf.

SPIVAK, Gayatri Chakravorty. Pode o subalterno falar? 1. ed. Trad. Sandra Regina Goulart Almeida; Marcos Pereira Feitosa; André Pereira. Belo Horizonte: Editora da UFMG, 2010 [1985].

THOMPSON, Edward Palmer. A formação da classe operária inglesa, v. I, A árvore da liberdade. Rio de Janeiro: Paz e Terra, [1987] 2011.

TRIPP, David. Pesquisa-ação: uma introdução metodológica. São Paulo, v. 31, n. 3. p. 443466, set./dez. 2005. Disponível em: http://www.scielo.br/pdf/ep/v31n3/a09v31n3.pdf. 